\title{
Impedimento configurador en la tríada protagónica de La ciudad y los perros: el recorrido cíclico en los triángulos jerárquicos
}

\section{Configurator Impediment in the Protagonist Triad of The Time of the Hero: The Cyclical Journey in the Hierarchical Triangles}

(c) UNAN-Managua

Recibido: mayo 2020 Aprobado: julio 2020

https://doi.org/10.5377/rll.v6i2.10728
Jesús Miguel Delgado Del Aguila

Universidad Nacional Mayor de San Marcos

Lima, Perú

tarmangani2088@outlook.com

https://orcid.org/0000-0002-2633-8101

\section{RESUMEN}

Recurriendo a la predominancia que le brinda René Wellek y Austin Warren al aporte empírico y la indeterminación que se origina al plantear postulados teóricos en la Literatura, pretendo demostrar la inconsistencia con la que están configurados los personajes el Jaguar, el Poeta y el Esclavo de La ciudad y los perros, los cuales asumo para este estudio como tríada protagónica. La demostración se basará en hallar estadios y conductas de los cadetes para fundamentar que sus identidades son consuetudinariamente variantes por la necesidad de alcanzar una posición significativa en entornos implicados con la violencia. En ese sentido, se designarán los valores convencionales para cada caso, sistematizados en gráfi cos de triángulos jerárquicos, de los que se observarán los recorridos

(inicialmente, ascendentes por exigencia) que se efectúan en ellos, los mismos que concluirán indefectiblemente en repeticiones cíclicas y desestabilizadoras.

Palabras claves: jerarquía, recorrido cíclico, violencia, personajes, empirismo, tríada protagónica

\section{SUMMARY}

Drawing on the predominance Rene Wellek and Austin Warren gives to the empirical contribution and the indeterminacy that originates when posing theoretical postulates in Literature, I intend to demonstrate the inconsistency with which the characters are configured the Jaguar, the Poet and the Slave of The Time of the Hero, which I assume for this study as a protagonist triad. The demonstration will be based on finding stadiums and behaviors of the cadets in order to establish that their identities are customarily variant due to the need to reach a significant position in environments implied with violence. In this sense, the conventional values for each case will be designated, systematized in hierarchical triangular graphs, from which the routes (initially, ascending due to requirement) will be observed, which will inevitably end in cyclic and destabilizing repetitions.

Keywords: hierarchy, cyclical journey, violence, characters, empiricism, protagonist triad

\section{INTRODUCCIÓN}

René Wellek y Austin Warren (1985, p. 30) co nsideran que la función estética es importante en el proceso de lectura de un texto literario. Sin embargo, al trabajar desde el reconocimiento de los estilos y la composición de la obra el propósito, se disuade en construir tratados científicos, filosóficos y políticos con una retórica particular y alturada. Ante ello, los autores brindan una reflexión que se orienta a buscar un replanteamiento de enfoque teórico o taxonómico:

El estudioso ha de traducir a términos intelectuales su experiencia de literatura, incorporarla en un esquema coherente, que ha de ser racional si ha de ser conocimiento. Puede ocurrir que el tema de su estudio sea irracional o al menos que contenga elementos fuertemente irracionales; pero no por ello se encontrará en condiciones distintas de las del historiador de la pintura o del musicólogo o, por lo demás, de las del sociólogo o del anatomista (Wellek y Warren, 1985, p. 17).

La relación que surge de la Literatura con la Filosofía es insoslayable, puesto que las ideas están presentes y se toman en consideración para indagar y localizar cuáles son los criterios imperantes; no obstante, esa 
operación lógica y automática que ha persistido durante mucho tiempo provoca desconfianza en cuanto producción de resultados exentos de un análisis directo y funcional (Wellek y Warren, 1985, p. 132). Por ende, se van erigiendo métodos literarios válidos que son solo perspectivas intelectuales y, en muchas ocasiones, se distancian del objeto de estudio.

Por ello, en esta investigación, se mostrará la construcción que presentan los distintos triángulos jerárquicos, los cuales se han consolidado de forma empírica para detectar una estructura de grados o rangos que se van estableciendo, según cada personaje, ya sea en mayor o menor intensidad, dentro del Colegio Militar Leoncio Prado y en función de la tríada protagónica. El modo de composición se representará en cada caso con los gráficos aludidos, en los que se colocará un valor determinante de forma gradual y descendente; con ello, se reducirá su potencial. Esa determinación que se hará no tendrá una validez absoluta, puesto que los planteamientos señalados tenderán a descomponerse con la lógica de la misma novela. No sucede lo mismo con los grados militares de los oficiales, que son invariables y respetables; por ejemplo, el general tiene un rango mayor que el del coronel y el comandante. En esta ocasión, se apreciará que las jerarquías logradas son alterables y variables; por lo tanto, tendrán la oportunidad de ser deconstruidas (por fuerzas externas que provienen de un tipo de violencia mayor). Esa alteración revelará un recorrido cíclico frecuente en cuanto que se desea hallar una utópica asimilación de identidad. Por esa razón, el rol excluido o poco simbolizado alcanzará la cima momentáneamente, pero esa colocación será transitoria, ya que se encuentra ubicada en un círculo recurrente y autodestructivo, en el que la violencia, en la mayoría de los casos, ha conllevado que las catalogaciones se inserten en una mecánica progresiva y retrospectiva. En términos semióticos, prevalecen embragues y desembragues (Blanco, 2009, p. 31) constantes de situaciones ya conocidas. Al observar que en los siguientes tratados no predominará una adaptación absoluta de categorías que definan a los tres personajes principales en sí, se asume que el Jaguar, el Poeta y el Esclavo son personajes redondos y no planos ${ }^{1}$, debido a que ellos irán cambiando de actitudes (implícita o explícitamente) por las circunstancias que se presentan en el texto. A la vez, esto es facilitado por la historia que brinda el narrador con respecto a sus vidas particulares (en el caso del Jaguar, se exterioriza su crecimiento desde pequeño hasta que logra casarse con Teresa).

Los ataques violentos que se patentizan en el Leoncio Prado de la novela, verbales y físicos, demandan una defensa en quien recibe estas acometidas, pero también se muestra un contraataque. Esta mecánica se aprecia por parte del victimario o la víctima, la cual se constituye como una cadena repetitiva y constante. Verbigracia, Ricardo Arana fue golpeado muchas veces, mas hizo justicia al acusar al serrano Cava; luego, el Jaguar lo mata por sentirse ofendido y, después, Alberto Fernández intentará vengarse al luchar contra él. Sin embargo, si se hace referencia a la igualdad de condiciones, se nota una alteración: el Esclavo recibe violencia física, aunque él no agrede de la misma forma a nadie; el Jaguar asesina, en cambio, lo que hacen las autoridades militares es obviar su caso.

La novela revela que los integrantes de la tríada protagónica (el Jaguar, el Poeta y el Esclavo) están implicados en la denominación de delator. Esta modalidad se pone en evidencia cuando ellos sienten la ausencia de su protección personal —el gráfico de los triángulos jerárquicos constata el proceso por el cual se moviliza cada uno al recurrir a la acusación-. Este recurso empleado es variante: el "soplón" deja de ser visto como un sujeto débil y traidor para adoptar una postura camaleónica y farsante, tanto así que niega haber delatado, por lo tanto, corroborará con la violencia. A propósito de ese tema, Alonso Cueto en su artículo "Las novelas de Mario Vargas Llosa: una teología del poder" (2011, pp. 570-571) precisó que los personajes están inmersos en la violencia, a causa de su intención por adquirir el poder. Esa necesidad se adhiere al ímpetu por rebelarse constantemente ante las entidades supremas. Eso explica por qué el Jaguar se aparta de normas y tradiciones en su institución para crear el Círculo e imponerse de forma autónoma.

Como son diversas las cualidades que permiten que se aluda a triángulos jerárquicos en torno a los protagonistas, se dividirá esta sección en cuatro tratados, los cuales irán graficados con su respectiva jerarquía construida y alterada. El objetivo de esta taxonomía gráfica es la de fundamentar la imprecisión con la que cuentan el Jaguar, el Poeta y el Esclavo, tal como lo proponen los teóricos René Wellek y Austin Warren. El primero

1. Edward Morgan Foster (1996, pp. 35-38) diferencia los conceptos narratológicos de personajes planos de los redondos de la siguiente manera. Los primeros conservan su naturaleza peculiar. Es posible inferir cuáles serán sus acciones: son previsibles e identificables para el lector. No adoptarán una condición que se desligue de la configuración estereotipada que le ha otorgado el autor: no evolucionan ni se involucran en situaciones trágicas. Incluso, esa modalidad termina siendo aborrecedora. Entretanto, los segundos desarrollan una pluralidad de emociones y acciones que impide conocer el porvenir de sus intervenciones en la obra literaria. Esa variabilidad sorprende y convence al lector: ese rasgo será instintivo en oposición a los personajes planos. 
aborda la ruptura de un orden causalista y previsible de las interacciones, que se caracterizan por ser simétricas (al establecer un contacto físico y verbal con un agente de iguales condiciones) y asimétricas (al existir incompatibilidades entre sujetos), con la finalidad de lograr un estadio momentáneo, cíclico y constante entre ambos modos. El segundo alude a la mecánica temporal de combate, la cual se rige en intensidad por las variables de ataque, defensa y contraataque. El tercero comprende las formas de combate, en las que el miedo o la autoconfianza se rigen como predominantes para asegurar la victoria o la derrota de una pelea. El cuarto tratado abarca cómo un cadete del Leoncio Prado se convierte en un "soplón"; se demostrará que esa actitud es equiparable al sentirse el personaje desprotegido.

\section{Las interacciones simétrica y asimétrica en la novela}

Las relaciones interpersonales que se erigen en La ciudad y los perros son necesarias para establecer vínculos recíprocos entre alumnos, a la vez, se coordinan variantes para convivir sin problemas en el Colegio Militar Leoncio Prado. Lo más fundamental en este punto es la diferenciación que se efectúa del tipo de interacción que se articula en ese medio, el cual presenta convencionalmente la siguiente estructuración: la simétrica, la espontánea y la asimétrica.

Primero, la interacción simétrica es definida por Lubomír Doležel (1999, pp. 149-150) como el recurso transitivo que es empleado por dos sujetos y distinguido como igual, para que el emisor logre una afección al receptor, siendo esta previamente acordada. Un ejemplo notorio es el de los integrantes del Círculo: todos ellos poseen algo en común, quieren transgredir las normas e infundir el terror en el Colegio Militar por medio de actos peligrosos. La interacción entre el Jaguar y los otros miembros del Círculo es recíproca y simétrica, puesto que el común denominador (la violencia) resulta similar en los integrantes, lo que les permite relacionarse con confianza y similitud de recursos y caracteres.

Segundo, las interacciones espontáneas revelan tratos desiguales, a pesar de que ambos personajes pertenecen a un mismo rango. Verbigracia, el hecho de estar en un mismo grado y sección implica una regularidad en las relaciones sociales. Recuérdense los tratos conflictivos entre el Poeta y el negro Vallano, quienes se enfrentaban verbalmente con constancia para demostrar su supremacía. Algunas situaciones las pondré a continuación:

«Tendré que pagarle al Jaguar por las preguntas salvo que Vallano me sople a cambio de cartas pero quién se fía de un negro» (Vargas Llosa, 2012, p. 18).

«Negro que ladra no muerde» (Vargas Llosa, 2012, p. 163).

«-Poeta — gritó Vallano-. ¿Tú has estado en el colegio La Salle?

-Sí - dijo Alberto-. ¿Por qué?

-El Rulos dice que todos los de La Salle son maricas. ¿Es cierto?

—No —dijo Alberto—. En La Salle no había negros» (Vargas Llosa, 2012, p. 161).

«'Poeta, hazme una poesía a esto' le dijo el negro Vallano y se agarró la bragueta. 'Ahorita te la hago', dijo el Poeta, 'déjame que me inspire'. Y al poco rato nos la recitaba: 'El pipí, donde Vallano, tiene la mano, parece un maní. Era bien fregado, sabía hacer reír a la gente, a mí se me prendió muchas veces y me daban unas ganas de machucarlo. Hizo buenas poesías a la Malpapeada, todavía tengo una copiada en el cuaderno de literatura: 'Perra: minetera eres, y loca; ¿por qué no te mueres, cuando el Boa te la emboca entera?'»(Vargas Llosa, 2012, pp. 306-307).

Otro caso de espontaneísmo se refiere al predominar una reciprocidad en la interacción, tomando en cuenta que los personajes que se confrontan pertenecen a dos rangos personales distintos (el Poeta, quien no es tímido ni temeroso, comparte sus experiencias con las del Esclavo, sin necesidad de que ellos lleguen muchas veces a la disputa). Estas desigualdades también provienen de qué tanto es respetado un sujeto que se incluye en una clasificación dominante — los del Círculo son temidos, pero lo es aún más el Jaguar, como cuaNdo propone el nombre de su agrupación: «[...] buscaremos un nombre para la banda. [...] ¿Los halcones? —insinuó alguien, tímidamente. [...] No — dijo el Jaguar-. Eso parece un juego. La llamaremos el Círculo» (Vargas Llosa, 2012, p. 65). 
Tercero, está la interacción asimétrica. Doležel (1999, pp. 149-150) observa esta peculiaridad en el momento en el cual las personas realizan actos distintos durante el intercambio verbal o físico. Es notoria en toda acción violenta que no puede ser resguardada o igualada, como cuando los del Círculo o el Jaguar abusan de Ricardo Arana, sin que él pueda enfrentarse con éxito.

Por ende, ¿bastará con que se observe la predominancia de una clasificación notoria en las interacciones de los cadetes? ¿Existe alguna otra manifestación verbal y física que no se adapte a las denominaciones ya señaladas? Estas preguntas conllevan cuestionar lo siguiente: ¿cómo es posible que Alberto Fernández, configurado como una postura distinta de la del Jaguar, logre colocarse a un mismo nivel para una confrontación y una pelea de verdad? ¿Esa actitud es parte de una interacción simétrica o asimétrica? En todo caso, ¿prevalece un tránsito entre los dos estadios? Luego del gráfico del triángulo jerárquico de los modos de interactuar, explicaré esa alteración.

\section{FORMAS DE INTERACTUAR}

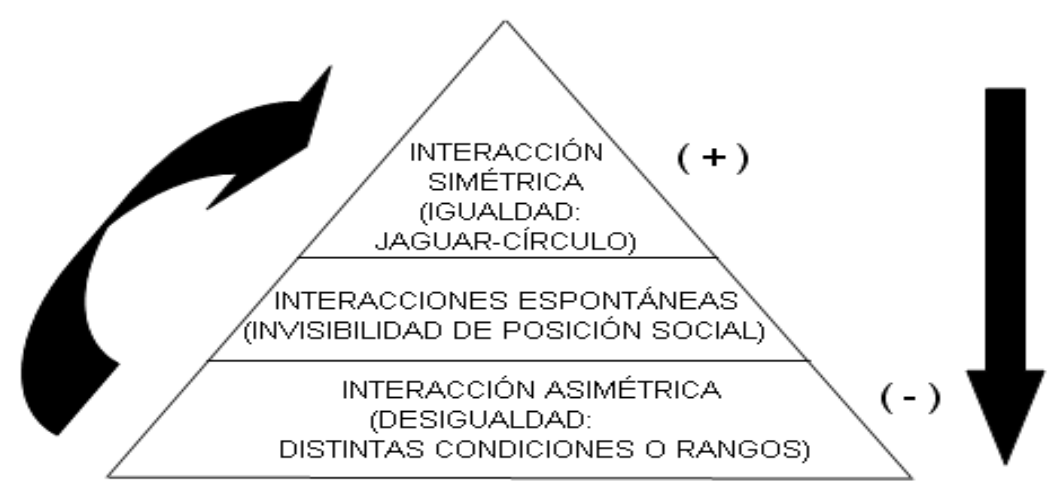

Figura 1 Formas de interactuar de la triada protagónica. Fuente: elaboración propia

Para René Wellek y Austin Warren (1985, pp. 32-33) importa mucho que se busque una propuesta esquemática más allá de la que postula el propio autor. A través de ese mecanismo, se revelará una verdad que es inherente a la literatura misma. Este gráfico del triángulo jerárquico acerca de las formas de interactuar presenta tres estadios imprescindibles para que el desarrollo del diálogo y la convivencia sean efectivos. Se muestra de modo ascendente el tránsito por el que se moviliza cada personaje para asegurar su mejor desenvolvimiento con otros. Primero, se halla la instancia de la interacción asimétrica. De por sí, esta es defectuosa, ya que los intercambios de lenguaje o acción no son los adecuados: se rigen por la violencia, la humillación, la desigualdad, etc. Este trato se produce debido a que entre ellos se consideran diferentes (menos o más importantes por la condición de violencia que impera en ese universo militar). Segundo, se exhibe el siguiente rango que se caracteriza por las interacciones espontáneas. En esa ocasión, se produce la conexión entre los implicados, aunque esta es por conveniencia (cada uno busca el provecho o lo más importante del otro). Para lograr ese propósito, no interesa conocer lo intrínseco de la personalidad de cada uno, sino obtener el objetivo. Las manifestaciones de violencia allí se exponen como una apariencia para no revelar la identidad de cada uno. Tercero, la interacción simétrica suscita al estar los personajes en las mismas condiciones de violencia. Eso permite que exista confianza entre ellos y traten de alcanzar sus fines, los cuales son mayormente antiéticos e ilegales. No obstante, sobre la base de la lectura de La ciudad y los perros, es posible mencionar que esa construcción que simula ser compacta, se desestructura por elementos externos. La violencia en sí resulta la primordial causa de esa desorganización, puesto que desestabilizan los tres estadios. Esa situación conlleva que el involucrado en el rango más bajo tenga la expectativa de conseguir la posición más alta; sin embargo, por lo explicado, no bastará pertenecer a esta, porque se tendrá el riesgo de volver a hallarse al inicio de la configuración del triángulo jerárquico. Por ende, el valor es importante, según Wellek y Warren (1985, p. 38), ya que permite dilucidar lo propio y lo natural en medio de 
una exposición relativa: esa atribución solo será posible y eficaz desde la experiencia.

En el texto, la discrepancia surge cuando un personaje de distinto rango modifica su manera de ser para entablar un diálogo o un combate con alguien que se encuentre por encima de él. A continuación, muestro cómo se produce esa confrontación entre Alberto Fernández y el Jaguar, quienes cuentan con preparación física para pelear muy diferente; en cambio, existe una motivación en el Poeta para concretar esa situación:

«- ¿Y eso qué importa? Lo fregabas y todos lo fregaban por imitarte. Le hacías la vida imposible. Y lo mataste.

—No grites, imbécil, van a oírte. No lo maté. Cuando salga, buscaré al soplón y delante de todos le haré confesar que es una calumnia. Vas a ver que es mentira.

—No es mentira — dijo Alberto-. Yo sé.

-No grites, maldita sea.

-Eres un asesino» (Vargas Llosa, 2012, p. 399).

Este ejemplo es el más significativo de la novela, ya que Alberto Fernández acusa al Jaguar y eso provoca que se peleen. No solo es en esa circunstancia, sino que después se genera un trato simétrico que les permite revelar sus propias confidencias (como el hablar sobre lo que piensan de ser "soplón", el posible asesino del Esclavo o las conductas informales de sus compañeros de sección). Este tránsito cualitativo en el Poeta, como se observa, se logra mediante la violencia: coloca a ambos personajes a un mismo nivel para la confrontación, el debate y hasta una amistad inicial. Algo similar ocurre con el Jaguar, quien atraviesa por un recorrido descendente: él, que se halla en la cima de la violencia, es atacado por los compañeros de su sección; a partir de ese instante, su condición es reducida masivamente a lo insignificante y lo humillante.

\section{Estrategia temporal de combate}

Esta formulación propone que existe una lógica causalista al momento de efectuar un ataque, distinguido por su condición de violencia, la cual presenta una forma verbal o física que producen daño en su víctima. Ante ello, se encuentra un segundo agente que tenderá a defenderse (soportará toda agresión y permanecerá en silencio) y, para finalizar, contraatacará. En La ciudad y los perros, quien manifiesta este ataque es el Jaguar (ya sea directamente, si es él quien se muestra físicamente, o de manera indirecta, si la agresión la ejecuta algún miembro de su partido). Lo cuestionable es que, en la novela, el contraataque posee una menor carga de agresividad, puesto que el Esclavo no recurre a la violencia para derrotar a sus agresores, sino para salvarse él mismo. El hecho de que se expulse al serrano Cava fue producto de las autoridades; Ricardo Arana solo logró su libertad con la condición de declarar quién era el culpable.

Ahora, si se tuviera que aplicar el mismo procedimiento con la defensa y el contraataque del Jaguar, las variables que componen la jerarquía cambian rotundamente. En el siguiente gráfico, se segmentan bien esos rangos propicios para un combate, mas el tratamiento desestructurado con respecto al Jaguar se explicará luego de ello.

La figura 2 del triángulo jerárquico en torno a la mecánica temporal de combate implica la articulación de tres componentes indispensables para su desarrollo: el contraataque, la defensa y el ataque. Estos adquieren un valor respectivo conforme están presentes progresivamente (de descendente a ascendente). Para su comprensión, es ineludible destacar que, para que el propósito de esta esquematización funcione, se debe tomar en cuenta el condicionamiento de la entidad o el personaje involucrado al requerimiento de poseer el grado supremo de este triángulo (el ataque). En el gráfico expuesto, se observa la atribución de cargas semánticas (positivas y negativas), en función de la posición que adoptan estos términos. En ese sentido, explicaré cómo estos se desarrollan individualmente para pretender un recorrido ascendente y fundamentaré el motivo por el que se suscita una reformulación a partir de fuerzas externas (la violencia). Primero, el contraataque se asume como una respuesta a un hecho violento, es decir, quien está tramando realizar un acto de esa índole ha recibido anteriormente un trato desigual o injusto. 


\section{Mecánica temporal de combate}

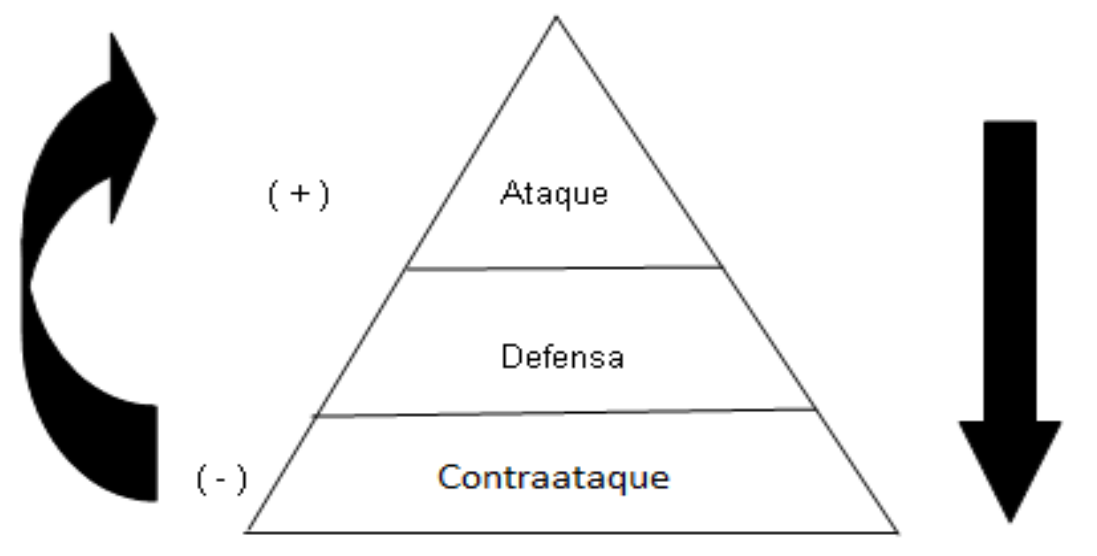

Figura 2. Mecánica temporal de combate en personajes militares. Fuente: elaboración propia.

Eso respalda su accionar. Por lo tanto, quien se halle en ese estadio está desligado de efectuar una acción antiética sin motivo alguno. En cierta forma, su accionar anhela una reivindicación, más que tratarse de una fijación exclusiva por dañar. Segundo, la defensa se retoma como un mecanismo que impide la extrapolación y la difusión de una conducta agresiva que se está recibiendo; por ello, se trata de una inacción o la inclusión de una violencia mínima que se orienta a resguardar y canalizar su propia interioridad: no repercute en otra persona, así sea el victimario con quien confronte. Tercero, el ataque es una posición netamente violenta, con el simple propósito de destruir a otra persona, con razones que no merecen ser consideradas para producir ese accionar. Quien adopte ese indicador, prácticamente, genera alteraciones y transgresiones a quienes están dispuestos a defenderse y contraatacar, pues su misma naturaleza destructiva hace que tengan la necesidad de que sea admirado por su nivel de violencia, sin importar el modo. No obstante, del gráfico del triángulo jerárquico de la mecánica temporal de combate, se infiere que lograr la posición suprema no asegura que quien se localice allí permanezca mucho tiempo. Eso significa que la estancia será perjudicada, ya que el atacante es sometido a recibir también una arremetida que escapa de la configuración de contraataque, es decir, prevalecerá el objetivo de que el atacante inicial sea destruido.

La alteración con el Jaguar ocurre mediante varios casos. Estos se evidencian cuando lo ataca indirectamente el Esclavo por acusar al serrano Cava; asimismo, con el intento fallido de agresión por parte de los alumnos de quinto año por haber ingresado recién a la institución (al hallarse en esa condición, se les denomina "perros"); o al ser denunciado por las autoridades y llevado a una celda, al descubrírsele su crimen contra Ricardo Arana y que revela al teniente Gamboa: "Todos lo batíamos, es la pura verdad, hasta cansarnos, yo más que los otros. No puedo olvidarme de su cara, mi teniente. Le juro que en el fondo no sé cómo lo hice. Yo había pensado pegarle, darle un susto" (Vargas Llosa, 2012, p. 445). La delación allí es un síntoma de los actos que ha estado produciendo en general ${ }^{2}$. Por otro lado, ante todos estos ataques, cabe destacar que la defensa del Jaguar no es tanto física, sino psicológica. Se vale de recursos para no perjudicarse por mucho tiempo (con rapidez, busca un recurso al crear el contraataque mismo: con la venganza hacia el delator del serrano Cava con el asesinato, el maltrato a los chicos del quinto año y la acusación a su sección entera por practicar actos prohibidos). Su contraataque no queda solo allí: se desestructura, intenta colocarse en posición de agresor, y, con ello, no dejarse provocar por nadie (crea el Círculo y, por ende, las constantes represiones físicas y psicológicas que recibirán los demás cadetes que pertenecen o no a su sección; para ello, adopta una postura silenciosa, agresiva y cínica, luego de que acusa a sus compañeros).

2 Alonso Cueto $(2012 ; 2013)$ sostuvo que una forma de delimitar una identidad es a través de la traición. Esta es una constante no solo del Esclavo al delatar al serrano Cava, sino del Poeta, quien se enamora de Teresa, sabiendo que es la chica a la que pretende Ricardo Arana, al igual que acusar al Jaguar y su sección. Por lo tanto, se infiere que las víctimas posteriormente resultaron ser victimarios. La postura de este crítico literario, junto con la de Víctor García de la Concha (2012, p. LXXXVII), determinan que existe esa modificación, equiparable al cambio de villano a héroe, como también las adaptaciones por las que pasan los personajes de desenvolverse de una manera peculiar en el colegio y, de otra, en la calle. 
En su mayoría, las defensas del Jaguar no suelen ser constantes: son temporales, duran corto tiempo; después, logra reponerse y contraataca con mayor violencia que la asimilada. Sintetizando, la complejidad en cuanto a la configuración de los personajes es ineludible desde lo literario, debido a que así se cumple la expectativa de lectura a la que se refieren René Wellek y Austin Warren (1985, p. 39), al sostener que un análisis en torno a adaptar un personaje a un tipo o viceversa es de poco provecho. Sin embargo, con la mecánica temporal de combate, se atribuye que la caracterización depende de las circunstancias, los deseos o lo inesperado.

\section{Las formas de combate: el miedo contra la autoconfianza}

Para empezar, es necesario retomar lo que plantean Wellek y Warren (1985, p. 45) en función de las emociones (en este caso, el miedo y la autoconfianza), quienes consideran que estas no son similares a las que se viven en la realidad: simplemente, están expresadas y liberadas, en una condición de modelizadas. Entonces, es un error colocar las sensibilidades de los personajes en el mismo plano real y objetivo de los lectores o el autor. Tomando en cuenta esta premisa, en este tratado, se observará el nivel de confianza que tienen los personajes y las consecuencias favorables que pueden alcanzar mediante este. Al inicio de la novela, en un diálogo establecido entre Alberto Fernández y Ricardo Arana, se pone en evidencia una mecánica que sirve para infundir respeto en el Colegio Militar (pelear y vencer).

¿Tú no has peleado nunca, no?

-Solo una vez —dice el Esclavo.

- ¿Aquí?

-No. Antes.

- Es por eso que estás fregado — dice Alberto-. Todo el mundo sabe que tienes miedo. Hay que trompearse de vez en cuando para hacerse respetar. Si no, estarás reventado en la vida.

- Yo no voy a ser militar.

-Yo tampoco. Pero aquí eres militar aunque no quieras. Y lo que importa en el Ejército es ser bien macho, tener unos huevos de acero, ¿comprendes? 0 comes o te comen, no hay más remedio. A mí no me gusta que me coman.

—No me gusta pelear — dice el Esclavo-. Mejor dicho, no sé.

—Eso no se aprende —dice Alberto_. Es una cuestión de estómago (Vargas Llosa, 2012, p. 26-27).

Aunque el diálogo final de Alberto no lo precise de manera correcta, será quien venza en las peleas el que gane el respeto de los demás, ya que cualquiera puede insertarse en una zona de combate; pero para poder triunfar sí se requiere una experiencia previa. Tal como sí se aprecia en un monólogo del Jaguar, cuando recuerda una de las formas que aprendió para pelear.

Ya me había trompeado en el colegio y peleaba muy bien, de chico mi hermano me enseñó a usar los pies y la cabeza. "El que se aloca está muerto", me decía. "Pelear a la bruta solo sirve si eres muy fuerte y puedes arrinconar al enemigo para quebrarle la guardia de una andanada. Si no, perjudica. Los brazos y las piernas se cansan de tanto golpear al aire y uno se aburre, desaparece la cólera y al poco rato estás con ganas de terminar. Entonces, si el otro es cuco y te ha estado midiendo, aprovecha y te carga". Mi hermano me enseñó a deprimir a los que pelean a la bruta, a agotarlos y a tenerlos a raya con los pies, hasta que se descuidan y le dan chance a uno de cogerles la camisa y clavarles un cabezazo. Mi hermano me enseñó también a manejar la cabeza a la chalaca, no con la frente ni con el cráneo, sino con el hueso que hay donde comienzan los pelos, que es durísimo, y a bajar las manos en el momento de dar el cabezazo para evitar que el otro levante la rodilla y me hunda el estómago. "No hay como el cabezazo", decía mi hermano; "basta uno bien puesto para aturdir al enemigo" (Vargas Llosa, 2012, pp. 348-349). 
En la novela, se aprecian tres casos dentro de la tríada protagónica, en su relación con el poco o el vasto conocimiento de las peleas. En una primera instancia, se halla el Jaguar. Él recibió instrucciones y adiestramientos en la calle; por esa y otras razones afines, pocas veces se le aprecia con miedo: casi nunca. Al respecto, en Retórica (1990) de Aristóteles, son múltiples las observaciones que hace el autor en función de la conservación de la virtud (imprescindible para forjar un espíritu ético en las personas). Entre sus planteamientos, sostiene que quien no tiene temores es porque en él predomina la confianza, y esta la poseen quienes no han sufrido ni un mal o se han librado de él a tiempo (Aristóteles, 1990, p. 339). Para el caso del personaje aludido, es notoria una seguridad destacable que se transforma en desvergüenza, al igual que mucha insensibilidad ante los vicios o el desprecio, debido a que se vale de lo terrible. Adoptando esa configuración desligada de la apropiación de los sentimientos compasivos, irá adquiriendo múltiples formas que lo destruirán como sujeto ético. En muchas ocasiones, no asumirá la responsabilidad de sus actos violentos, ni considerará el problema como personal. El Jaguar goza de ese estado: se jacta de ser el más fuerte y luchador de los cadetes. Eso suscita que en el Colegio Militar Leoncio Prado muchos cadetes ${ }^{3}$ pretendan ser como él, tanto así que buscan asemejarse en cualquier peculiaridad suya, como cuando el Esclavo se percata de algo notorio en el Poeta, y él lo confirma: «Es verdad [...]. Me estoy riendo como el Jaguar. ¿Por qué lo imitan todos?» (Vargas Llosa, 2012, p. 26).

Debajo de la primera posición, se halla el Poeta. Este personaje extrapola la violencia en pocos casos. Se hace respetar por medio de agresiones (más de carácter verbal). Por ende, cuenta con el siguiente criterio: «Por eso que estás fregado - dice Alberto-. Todo el mundo sabe que tienes miedo. Hay que trompearse de vez en cuando para hacerse respetar. Si no, estarás reventado en la vida» (Vargas Llosa, 2012, p. 26). Su caracterización se rige por tener un conocimiento en función de la forma de pelear; en consecuencia, sus recursos empleados son de un nivel moderado o gradual. Su manera de combatir es algo torpe (no logra vencer ni hacer mucho daño al Jaguar cuando lo enfrenta). Eso sí, no se acobardará ante las peleas, ya que constantemente siente que su posición se halla arriesgada entre el temor y la confianza. Bastará que muestre una actitud camaleónica para que no se represente tan callado e impotente como Ricardo Arana, como tampoco, sobrepase los poderes del Jaguar: las interacciones regidas con estos criterios permitirán una fácil socialización entre los demás cadetes.

El tercer rango, y el menos implicado, es el del Esclavo. En este, el temor a pelear es la primordial limitación y la causa verdadera de que se atraigan todos los pesares internos que puedan ocasionarle sus demás compañeros. Una interrogante afín se formula el protagonista: «No puedo fiarme de nadie', pensó. '¿Por qué todos son mis enemigos?» (Vargas Llosa, 2012, p. 160). Su inacción y su interpasividad provocarán ese desenlace consuetudinario. En un diálogo que realiza Alberto Fernández con el Jaguar, se muestra la actitud con la que cuenta Ricardo Arana en torno a su reputación: «El Esclavo era un buen muchacho, tú no sabes lo que es eso. Él era buena gente, no se metía con nadie. Lo fregabas todo el tiempo, día y noche. Cuando entró era un tipo normal y, de tanto batirlo, tú y los otros, lo volvieron un cojudo. Solo porque no sabía pelear» (Vargas Llosa, 2012, p. 398). El Esclavo no se ha peleado casi nunca en su vida (solo una vez, como se especifica en el diálogo que se citó anteriormente, pero no lo ha hecho en el Colegio Militar), tiene miedo (no posee cualidades violentas). En la novela, no se muestra ni un trato agresivo de su parte hacia los chicos de años inferiores (no bautiza severamente a los "perros" cuando cursa el quinto año, se obvia esa parte o no existe, aunque por tradición militar debería haberlo hecho).

Estas tres maneras de ver la tríada protagónica, con respecto a la confianza y el conocimiento sobre las peleas, permiten distinguir una clasificación jerárquica que activa la importancia del recurso de la violencia. ¿Pero qué sucede si la violencia se ejecuta desde un rango inferior? Se genera una alteración en ese establecimiento: la obra literaria presenta esa cualidad. Esta modificación se explicará luego en la figura del triángulo. El triángulo jerárquico en torno a las formas de combate se rige del orden predeterminado que se muestra con sus valores de menos a mayor importancia. El primero se enfoca en abordar el temor ${ }^{4}$. Para ello, se lo ha colocado

3 En el artículo "La ciudad y los perros" (2005, p. 124) de Sarah Osgood Brooks, la crítica propone que definitivamente no debe considerarse como un objetivo la enseñanza de valores en la institución militarizada, ya que existe una deliberación de acciones que los corrompen.

4 Gustavo Correa en su artículo "El héroe de la picaresca y su influencia en la novela moderna española e hispanoamericana" (1977, p. 90) planteó que el miedo se patentiza porque prevalece la conexión entre lo justo y la ausencia de compasión (tópicos que se abordan desde la violencia y sus variantes, como el machismo y la hombría). 
como indicador por ser un síntoma de que el personaje involucrado no posee los mecanismos fundamentales para evadir y confrontar una instancia de violencia. En caso de que se supere ese rasgo, existe un traslado al

\section{Formas de combate}

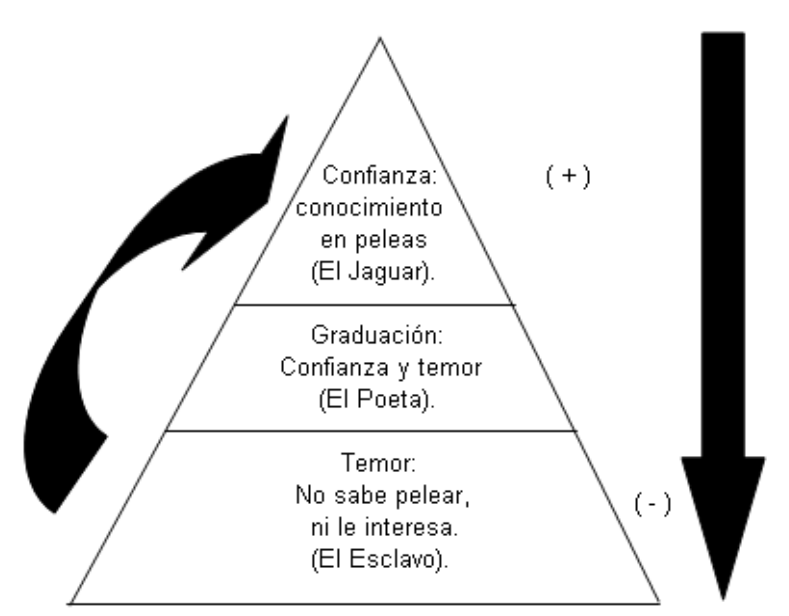

Figura 3. Formas de combate en la tríada protagónica. Fuente: elaboración propia

segundo estadio que se halla en la figura 3, caracterizado por la apropiación de atributos que facilitan una mejoría con respecto al grado inicial porque se ha incluido la confianza; sin embargo, aún es notoria la imperfección para aminorar la totalidad de violencia que se le presenta como amenaza, debido a que conseguir reducirla o contrarrestarla requiere una formación que le exige un tiempo y un espacio incompatibles e inalcanzables para una determinada situación ${ }^{5}$. Sintetizando, esa variación es verosímil y acapara una globalidad considerable. Es propio de los estudios literarios ese rasgo, distinguido por los abordajes que prevalecen en lo social, lo tradicional, lo convencional, lo normativo, lo simbólico y lo mítico (Wellek y Warren, 1985, p. 112).

La estadía en la escuela militar también es un impulso para que exista ese criterio de tener que adoptar una actitud frente a la realidad, así no sea del todo agradable, tal como lo expresa el Poeta: «Aquí eres militar, aunque no quieras. Y lo que importa en el Ejército es ser bien macho, tener unos huevos de acero, ¿comprendes? 0 comes o te comen, no hay más remedio. A mí no me gusta que me coman» (Vargas Llosa, 2012, p. 26). Asimismo, los críticos literarios Ricardo Doménech (1964), George McMurray (1973, p. 579), María Eugenia Moreno Cambara (1987, p. 43) y Frederick Nunn (1987, pp. 459-460) han fundamentado que los encargados de dirigir a los estudiantes del Colegio Militar Leoncio Prado no necesariamente están aptos para adiestrarlos de una forma semejante a la educación que podrían recibir en una institución no castrense. De algún modo, es notoria la diferencia: el trato autoritario, severo y deshumanizante. En ese sentido, si el Esclavo supiera pelear, hubiera derrocado al Jaguar. Recuérdese que él pudo vencer el miedo al delatar al serrano Cava. Además, la fase de violencia se sostiene de modo complejo, puesto que es en sí misma un proceso de desequilibrio paranoico: busca destruir al otro, debido a que es peligroso; por lo tanto, se ataca antes de ser maltratado. Ricardo Arana transforma ese orden establecido de la violencia. Luego de ser una víctima

constante y contar con motivos y conocimiento sobre cómo agredir, él sabe perfectamente qué es lo que ridiculiza y ofende más a una persona por experiencia propia. Prácticamente, está preparado para ser un transgresor de las leyes; mas no sucede así: en esta obra literaria, no ocurre el arrebato del poder por parte del Esclavo. Él se queda en ese tercer momento de formas de combate, aunque sí pasa con el Poeta y el Jaguar: ellos atravesaron las tres etapas ya mencionadas. El Jaguar no sabía pelear desde el inicio: lo aprendió en la calle; eso le generaba

5 Alonso Cueto en su artículo "Las novelas de Mario Vargas Llosa: una teología del poder" (2011, p. 579) y Guadalupe Nettel en "El hombre en cautiverio: modelos de masculinidad en Los cachorros y La ciudad y los perros" (2011, p. 86) asumieron que la preparación física es ineludible para poder luchar con eficacia, además de que ese entrenamiento suscitará que los personajes sean reconocidos por el resto de alumnos (en relación con su capacidad para combatir). 
autoconfianza, mas no de manera cabal (no podía vencer a cualquiera). Recién en el colegio, logrará la máxima jerarquía. Asimismo, este personaje puede insertarse en el tercer rango cuando va a ser bautizado por los de quinto: él quita esa creencia y se coloca por encima de los agresores. Por ello, consigue una deconstrucción jerárquica. Con el Poeta, ocurre igual: no sabe pelear, lo aprende en el colegio y se posiciona al nivel del Jaguar al enfrentarse a él. Aunque no consigue permanecer allí: regresa a su estado anterior e intermedio. De todos modos, en ese intento de arrebatarle el poder se consigue una alteración: no se trata del más fuerte ni del que mejor sabe combatir; más bien, todo depende de exterminar el miedo almacenado y vengarse.

\section{El "soplón": la impotencia ante la desprotección}

En el libro Teoría literaria (1985, p. 31) de René Wellek y Austin Warren, se expone que una novela no es completamente cierta. Con mayor razón, la composición de los personajes introducidos no es precisa: no se somete a una lógica por el propio carácter de la literatura, que es más ficción, que realidad. En ese sentido, ¿cómo se puede tratar la configuración que se le atribuye a los personajes de La ciudad y los perros al aludir al acto delativo? Como ya se señaló en temas anteriores, la tríada protagónica recurre a la caracterización de "soplón" al encontrarse en una situación desprotegida y angustiada, en la que su reputación peligra y se estanca — se asocia con el autor, quien critica deliberadamente las fallas pedagógicas del Colegio Militar, perteneciente a una sociedad tercermundista-. El Esclavo acusa al serrano Cava, porque ya no hay quién lo ayude a vivir menos angustiado. El Poeta delata al Jaguar y su sección, puesto que piensa que nadie más que la Ley podrá castigar al homicida; él ni nadie podrán hacerlo. Para finalizar, el Jaguar culpa a sus compañeros, debido a que no quiere verse como único responsable. Pretende implicar a los demás. ¿Pero cuáles son los criterios que permiten que esta acción se desemboque? La relación que se establece cualitativamente es con el nivel de protección en contacto con la confianza de uno mismo.

En un primer momento, se observa que una persona se siente más protegida cuando no existe la manera de desequilibrar su seguridad interna, que lo conduce a no dudar de sus cualidades. Esto también es asimilado por la atmósfera de seguridad creada por toda una colectividad que acompaña al sujeto en cualquier eventualidad (sobre todo, en situaciones de peligro). En una segunda instancia, se halla un estado de emergencia en el personaje, ya que la protección y la compañía de los seres que salvaguardan al individuo resultan peligrosas. Ante ello, el protagonista adopta una postura angustiada, en la que el silencio y la reflexión actúan de forma paralela. En consecuencia, crean suposiciones o porvenires — recuérdese la actitud insegura y enfermiza de Ricardo Arana durante la delación al serrano Cava-: ideas apresuradas que llevan a una verdad infundada (como cuando el Poeta cree que, de todos modos, el asesino del Esclavo es el Jaguar por cuestiones de venganza). Al respecto, insertaré las deducciones que menciona Alberto Fernández al personaje incriminado: «Te van a expulsar [....]. Y quizá te manden a la cárcel [...]. Eres una mierda, Jaguar [...]. Me gustaría que te metieran en la cárcel [...]. Una mierda [...]. Un asesino. Tú mataste al Esclavo [...]» (Vargas Llosa, 2012, p. 397).

Para finalizar, debajo de los dos momentos anteriores, se halla el que se desvincula del respaldo moral colectivo, para refugiarse en una soledad destructiva, motivo por el cual el personaje tenderá a delatar al culpable que lo ha llevado a ese estadio autodestructivo.

Ahora que es más específica la jerarquía de los tres momentos que atraviesa un personaje para convertirse en un "soplón", se percibirá, de igual manera, que no es primordial una importancia por encontrarse en la cima de estos estadios, pues la desestructuración se logra cuando el "soplón" recupera su confianza, y, con ella, consigue también insertarse de nuevo en el rango superior de este triángulo jerárquico, el cual se observa en la figura 4. Asumiendo que en este gráfico triangular jerárquico impera una lógica causalista, en la que a toda acción le corresponde una reacción, es notoria la configuración que va adquiriendo cada una de estas tres atribuciones (desprotección, silencio y protección) de acuerdo con cómo se vaya ascendiendo a cada posición. La primera instancia es la de la desprotección o la soledad, que se manifiesta a partir de haber "soplado" o delatado algún suceso. Consecuentemente, se muestra el siguiente rango, distinguido por el silencio y la angustia que genera el primer accionar. Para finalizar, luego de los dos estadios anteriores, se establece el tercer instante, que se produce por la protección y la confianza que se le adhiere, las mismas que anulan toda sensación de riesgo o peligro. Este 
último trance permite que la situación se estandarice con normalidad. Sin embargo, fuerzas externas (como la venganza, el odio, la insatisfacción y cualquier otra emoción de violencia) conllevarán que ese triángulo jerárquico consolidado se desestructure. En ese sentido, quien esté implicado en ese tránsito (ascendente) estará regido por una dinámica constante de repetición y ciclismo (el ritmo consuetudinario de ascenso a descenso será peculiar en la gráfica del triángulo jerárquico).

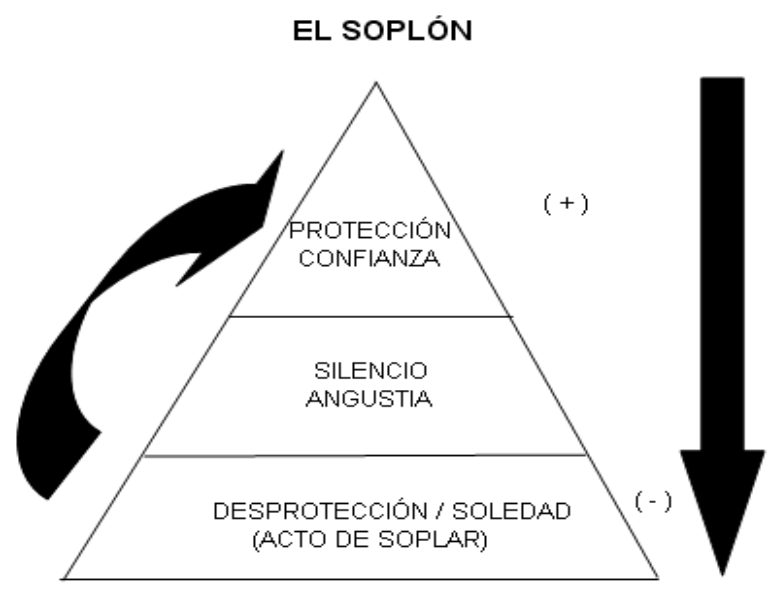

Figura 4. Composición cíclica del "soplón"

Esta modificación ocurre cuando el individuo se revela ante su posición denigrante de soplón, para recuperar su confianza y su postura anterior. En este caso, es necesario que el personaje reconozca todo ese proceso. Recuérdese cuando el Poeta y el Jaguar se encontraron en la misma celda:

«-Yo no he matado a nadie. Juro que no, mi teniente.

—Lo veremos —dijo Gamboa-. Es mejor que confieses todo.

—No tengo nada que confesar — gritó el Jaguar- Lo de los exámenes, lo de los robos, es cierto. Pero yo no soy el único. Todos hacen lo mismo. Solo que los rosquetes pagan para que otros roben por ellos. Pero no he matado a nadie. Quiero saber quién le ha dicho eso.

—Ya lo sabrás — dijo Gamboa-. Te lo dirá en tu cara» (Vargas Llosa, 2012, p. 368).

Será en esa oportunidad en la que él alcance ese tránsito de la inseguridad a la confianza. Por un instante, piensa que no debería decirle al Jaguar que él mismo lo ha acusado, pero después cambia esa forma de pensar, le revela que él lo delató y no se quedará contento con ello, porque hará lo imposible para que lo metan a la cárcel. La capacidad de Alberto Fernández, en alterar su conducta, se logra por su pretensión de venganza — de nuevo, es la violencia la que desestructura una jerarquía establecida-. Entretanto, José Miguel Oviedo (2012, p. XXXIX) y Ricardo González Vigil (2013) argumentaron que la noción de "soplón" en el Jaguar se trata de un código de honor: más que tratarse de un acto de venganza es un acto de bajeza o simplismo que repudia; por eso, no ejecutará esa modalidad de expresarse.

\section{CONCLUSIONES}


El análisis realizado al Jaguar, el Poeta y el Esclavo (la tríada protagónica) se basó en la inferencia de que ellos transitan por modificaciones internas que son evidentes en el texto. A través de la esquematización ascendente y descendente de los triángulos jerárquicos, se constató la ruptura de toda autodeterminación o evolución de los personajes (causalismo patentizado por el interés de asumir un mayor poder), para apreciar un recorrido cíclico y autodestructivo que es imperante en cuanto que se anhela estabilizar los actos o las determinaciones de los implicados. Esas alteraciones e inestabilidades fueron fundamentadas mediante los gráficos convencionales, formulados empíricamente a partir de la lectura. Verbigracia, se comprendió el dinamismo de la conformación esporádica de las estrategias de combate, al igual que su desestructuración. Este análisis fue posible por lo que propusieron René Wellek y Austin Warren en su texto Teoría literaria (1985), quienes se respaldan de la noción de que para una interpretación no necesariamente se debe recurrir a postulados teóricos preestablecidos, con el objetivo de expresar una verdad dentro del texto. Por lo tanto, lo empírico en este artículo fue de utilidad para confrontar las ideas inherentes que rigen la configuración indeterminada de los personajes, al igual que de sus acciones.

Con esta investigación, se logra percibir la inmediatez de un carácter o una acción que se desenvuelve en un contexto violento, tal como se demostró con la configuración del "soplón", a quien se le atribuye patrones de conducta débil e inactiva, mientras que su desempeño posibilita la modificación de todo un universo caracterizado y organizado por la violencia que ha constituido el Jaguar en el Colegio Militar Leoncio Prado. En ese sentido, la seguridad de contar con la determinación y la estabilidad de los personajes resulta inadmisible: el Esclavo se rebela contra ese orden, el Jaguar se humaniza para aminorar las fechorías realizadas y el Poeta se adapta a dos regímenes distintos para sobrevivir.

Ese dinamismo no es prescindible: permite la construcción de una identidad en los protagonistas. Ellos se están educando y madurando con las experiencias pertenecientes a su instrucción escolar-militar, como también son de utilidad las vivencias con las que confrontan fuera de esa institución castrense. Esa adquisición de nuevos conocimientos se identifica más en las interacciones que tienen (simétrica y asimétrica) y el propósito de las múltiples peleas (quien gana más combates está generando que se autodetermine como un sujeto más seguro de sí mismo).

\section{REFERENCIAS}

Aristóteles (1990). Retórica. Traducción a cargo de Quintín Racionero. Madrid: Gredos.

Blanco, D. (2009). Vigencia de la semiótica y otros ensayos. Lima: Fondo Editorial, Universidad de Lima.

Brooks, S. O. (2005). La ciudad y los perros. Journal of Latin American Geography, 4(2), 123-125.

Correa, G. (1977). El héroe de la picaresca y su influencia en la novela moderna española e hispanoamericana. Thesaurus, 32(1), 75-94.

Cueto, A. (2011). Las novelas de Mario Vargas Llosa: una teología del poder. Estudios Públicos, (122), 568-588.

Cueto, A. (2012). La ciudad y los perros: el itinerario moral. En Conferencia impartida en Universidad de Granada (pp. 1-10). Alicante: Biblioteca Virtual Miguel de Cervantes.

Cueto, A. (2013). La ciudad y los perros. El itinerario moral. En Congreso Internacional La Ciudad y los Perros y el Boom Hispanoamericano. Lima: Casa de la Literatura Peruana.

Delgado Del Aguila, J. M. (2012). Interacciones condicionadas. El Poeta de La ciudad y los perros (1963). En III Encuentro de Jóvenes Investigadores en Literatura Peruana. Lima: Universidad Nacional Mayor de San Marcos.

Delgado Del Aguila, J. M. (2017). Protagonismo violento y modos de representación en La ciudad y los perros (1963). Tesis de licenciatura. Universidad Nacional Mayor de San Marcos. 
Delgado Del Aguila, J. M. (2018a). Causalismo e impacto violentos en La ciudad y los perros. Cuadernos del Hipogrifo, (9), 26-39.

Delgado Del Aguila, J. M. (2018b). Los espacios de la violencia (direccionalidad) en La ciudad y los perros (1963): caso del Esclavo. Revista Espergesia, 5(1), 39-52.

Delgado Del Aguila, J. M. (2019a). El causante de la violencia (dominante): el Jaguar de La ciudad y los perros (1963) de Mario Vargas Llosa". La Ventana. Revista de Estudios de Género, 6(49), 141-180.

Delgado Del Aguila, J. M. (2019b). Violencia protagónica en La ciudad y los perros (1963) de Mario Vargas Llosa: enfoques narratológico y semiótico. Káñina, 42(2), 133-155.

Doležel, L. (1999). Heterocósmica. Ficción y mundos posibles. Traducción a cargo de Félix Rodríguez. Madrid: Arco/Libros.

Doménech, R. (1964). La ciudad y los perros, de Mario Vargas Llosa. En Gracia, J. y Marco, J. (Coords.). La llegada de los bárbaros: la recepción de la literatura hispanoamericana en España, 1960-1981 (pp. 311-312).

García de la Concha, V. (2012). Una novela en círculo. En Vargas Llosa, M. La ciudad y los perros. Edición conmemorativa del cincuentenario (pp. LXI-C). Italia: Alfaguara, Real Academia Española.

González Vigil, R. (2013). La ciudad y los perros es un clásico que puede leerse sin conocer Lima (entrevista de Juan Carlos Soto), La República.

McMurray, G. (1973). Form and Content Relationships in Vargas Llosa's La ciudad y los perros. Hispania: A Journal Devoted to the Teaching of Spanish and Portuguese, 56(3), 579-586.

Moreno Cambara, M. E. (1987). La corrupción: tema central de la novela La ciudad y los perros. Tesis de licenciatura. Universidad de San Carlos de Guatemala.

Morgan Foster, E. (1996). Personajes planos y personajes redondos. En Sullá, E. (Ed.). Teoría de la novela. Antología de textos del siglo XX (pp. 35-38). Barcelona: Crítica.

Nettel, G. (2011). El hombre en cautiverio: modelos de masculinidad en Los cachorros y La ciudad y los perros. Estudios Públicos, (122), 78-95.

Nunn, F. (1987). Mendacious Inventions, Veracious Perceptions: the Peruvian Reality of Vargas Llosa's. La ciudad y los perros. Americas; a Quarterly Review of Inter-American Cultural History, 3(4), 453.

Oviedo, J. M. (2012). La primera novela de Vargas Llosa". En Vargas Llosa, M. La ciudad y los perros. Edición conmemorativa del cincuentenario (pp. XXXI-LIX). Italia: Alfaguara, Real Academia Española.

Vargas Llosa, M. (2012). La ciudad y los perros. Edición conmemorativa del cincuentenario. Italia: Alfaguara, Real Academia Española.

Wellek, R. y Warren, A. (1985). Teoría literaria. Traducción a cargo de José María Gimeno. Madrid: Gredos. 